\title{
Dialectal variation of duration patterns in Finnmark North Sámi quantity
}

\author{
Hiovain, Katri
}

2020-04

pÿHiovain , K , 'imko , J \& Vainio , M 2020 , ' Dialectal variation of duration patterns in

Finnmark North Sámi quantity ' , Journal of the Acoustical Society of America, vol. 147 , no.

pÿ4 , pp. 28172828 . https://doi.org/10.1121/10.0000994

http://hdl.handle.net/10138/319731

https://doi.org/10.1121/10.0000994

publishedVersion

Downloaded from Helda, University of Helsinki institutional repository.

This is an electronic reprint of the original article.

This reprint may differ from the original in pagination and typographic detail.

Please cite the original version. 


\section{Dialectal variation of duration patterns in Finnmark North Sámi quantity}

Katri Hiovain, Martti T. Vainio, and Juraj Šimko

Citation: The Journal of the Acoustical Society of America 147, 2817 (2020); doi: 10.1121/10.0000994

View online: https://doi.org/10.1121/10.0000994

View Table of Contents: https://asa.scitation.org/toc/jas/147/4

Published by the Acoustical Society of America

\section{ARTICLES YOU MAY BE INTERESTED IN}

Introduction to the special issue on the phonetics of under-documented languages

The Journal of the Acoustical Society of America 147, 2741 (2020); https://doi.org/10.1121/10.0001107

Acoustic correlates of plosive voicing in Madurese

The Journal of the Acoustical Society of America 147, 2779 (2020); https://doi.org/10.1121/10.0000992

An acoustic description of Mixean Basque

The Journal of the Acoustical Society of America 147, 2791 (2020); https://doi.org/10.1121/10.0000996

Tonal mapping of Xi'an Mandarin and Standard Chinese

The Journal of the Acoustical Society of America 147, 2803 (2020); https://doi.org/10.1121/10.0000993

A formant study of the alveolar versus retroflex contrast in three Central Australian languages: Stop, nasal, and lateral manners of articulation

The Journal of the Acoustical Society of America 147, 2745 (2020); https://doi.org/10.1121/10.0001012

How "mixed" is mixed language phonology? An acoustic analysis of the Michif vowel system

The Journal of the Acoustical Society of America 147, 2989 (2020); https://doi.org/10.1121/10.0001009

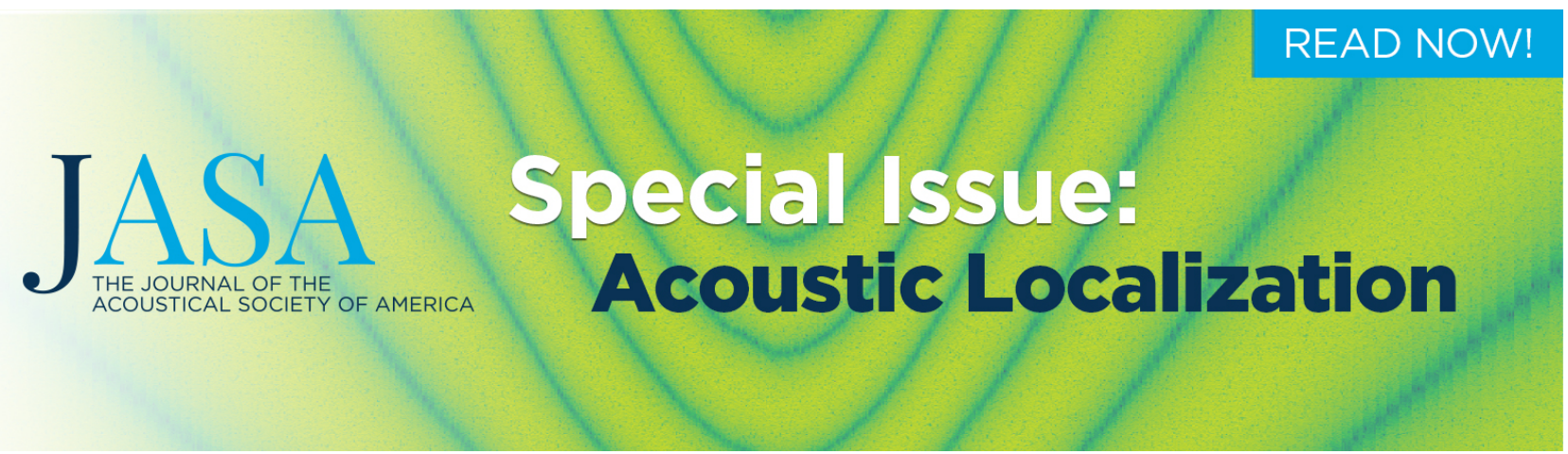




\title{
Dialectal variation of duration patterns in Finnmark North Sámi quantity
}

Katri Hiovain, ${ }^{\text {a) }}$ Martti T. Vainio, ${ }^{\text {b) }}$ and Juraj Šimkoc)

Department of Digital Humanities, University of Helsinki, Siltavuorenpenger 1A, 00014 Helsinki, Finland

\begin{abstract}
:
Ternary length contrast is a rare phonological feature, investigated here both in terms of its realization and possible undergoing changes. In North Sámi, a phonetically under-documented and endangered Fenno-Ugric language spoken by indigenous people in Northern Europe, the ternary quantity contrast is assumed to be signalled by a progressive lengthening of a consonant and a compensatory shortening of the previous vowel. This study evaluates this assumption and compares the realization of the length contrasts in two dialects, the Western and Eastern Finnmark North Sámi. The results show that while the contrast between the short and the two longer quantities is robustly signaled regardless of the dialect, the durational differences between the two longer quantities are maintained only in the Eastern dialect. On the other hand, a vowel quantity contrast independent of the quantity of the following consonant is present in the Western but not in the Eastern dialect. Further, comparing the phonetic realization of the ternary quantity contrast for speakers of different ages presents evidence of a language change: the results indicate an ongoing neutralization of the ternary contrast in younger speakers, which points to a possible disappearance of this rare typological feature in Finnmark North Sámi. (C) 2020 Acoustical Society of America.

https://doi.org/10.1121/10.0000994
\end{abstract}

(Received 3 May 2019; revised 9 October 2019; accepted 16 October 2019; published online 30 April 2020)

[Editor: Benjamin V. Tucker]

Pages: $2817-2828$

\section{INTRODUCTION}

Ternary quantity opposition of consonants, a phonological system where contrasts are signalled by three-way differences in segmental duration, is considered a crosslinguistically extremely rare typological feature (Ladefoged and Maddieson, 1996; McRobbie-Utasi et al., 2007). It is known to occur only in a small number of languages, primarily belonging to the Finnic subgroup of the Uralic family, for example, Estonian and Livonian (Markus et al., 2012), and various Sámi languages (Bye et al., 2009). With the exception of Estonian, these Finnic and Sámi languages are all seriously endangered or (nearly) extinct, and so is the multitude of various phonetic realizations of this interesting phonological phenomenon.

In this work, we investigate the durational characteristics underlying the ternary quantity system of one of these endangered languages, the Finnmark variety of North Sámi. We compare the phonetic realization of the contrasts in its two sub-varieties, Western and Eastern dialects, and examine potential language change patterns pertaining to this phenomenon. We also evaluate a possible effect of the North Sámi orthography on the ways speakers use segmental duration to signal appropriate contrasts.

The Sámi people are the only officially recognized indigenous group within the European Union, and their languages are all classified as endangered or extinct. The

\footnotetext{
a)Electronic mail: katri.hiovain@helsinki.fi, ORCID: 0000-0002-6787-4752.

${ }^{b)}$ ORCID: 0000-0003-2570-0196.

${ }^{c)}$ ORCID: 0000-0002-8693-9646.
}

research tradition of the Finno-Ugric languages distinguishes ten Sámi languages, see Fig. 1 (for thorough presentation of history and structure of the Sámi languages, see Korhonen, 1981; Sammallahti, 1998). The languages form a language continuum, where adjacent varieties are to some extent mutually intelligible. Geographically, the Sámi speaking region spans the areas between central Sweden and the tip of the Kola peninsula in northwest Russia (Sammallahti, 1998; Scheller, 2011). Even the largest of the Sámi languages, North Sámi, with estimated 20 000-24 000 speakers (Kahn and Valijärvi, 2017; Aikio et al., 2015), is classified as "definitely endangered (children not speaking)" by UNESCO (Moseley, 2010).

The North Sámi language, with less than 20000 speakers in Norway, around 5000 in Sweden, and around 2000 in Finland, is divided into three main dialect groups: (Western and Eastern) Finnmark, Torne, and Sea North Sámi. The Finnmark North Sámi dialect is spoken in the northern parts of Norway and Finland, see Fig. 1, and comprises the Western and Eastern dialects with various phonetic and phonological differences including the realization of the quantity contrasts. All Finnmark North Sámi speakers are at least bilingual and often receive their education in the majority state language, i.e., Norwegian or Finnish.

Even though North Sámi is still the predominant language in a few municipalities situated in the traditional Sámi areas (Kárášjohka and Guovdageaidnu in Norway, and possibly also in Ohcejohka in Finland), the majority state languages are also used in daily life (local services, media, etc.) and thus can be expected to influence some phonetic characteristics of the Sámi varieties (Hiovain and Šimko, 


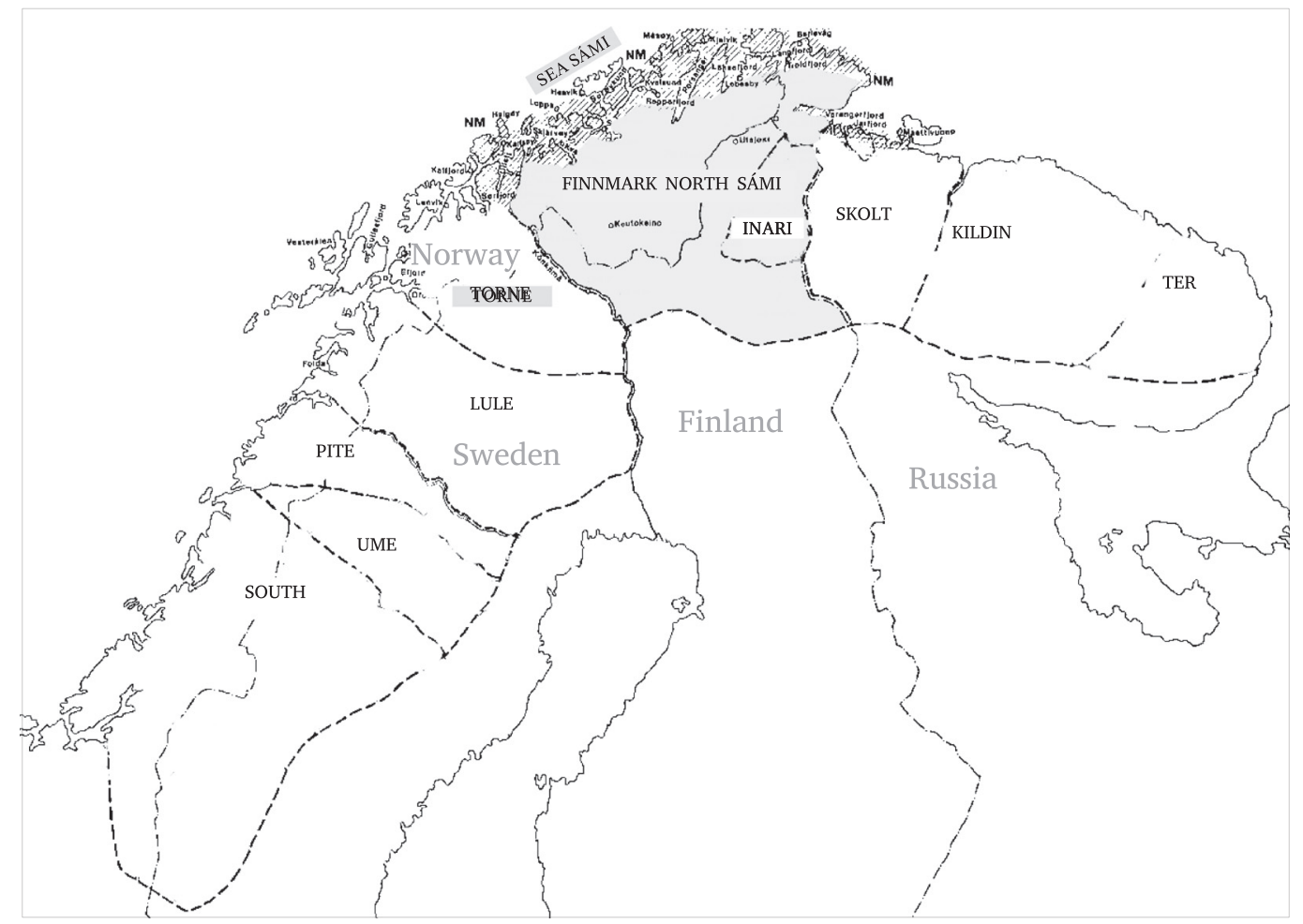

FIG. 1. Map of the Sámi languages and their speaking areas with Finnmark North Sámi area highlighted with grey color. Adapted from Korhonen (1981).

2019). Nevertheless, in a traditional dialectal analysis by, e.g., Sammallahti (1998), the majority language influence is not taken into account, and the dialectal borders are different from the state borders. The modern North Sámi language situation is described in more detail in Aikio et al. (2015).

\section{A. General characteristics of quantity opposition}

The term quantity usually refers to contrastive durational patterns acting as an independent variable in a language (Lehiste, 1970). This means that a (usually binary) difference in the length of even one of the segments in the word can change a lexical meaning or grammatical status of the word. For example, in the minimal pair in North Sámi, gohpi, "a pit"-gohppi, "a bay," segmental length is used to separate two different lexical meanings. In another kind of North Sámi example, the duration of $[\boldsymbol{v}]$ provides grammatical contrast (word meaning "picture"): gova (GEN.SG)govva (NOM.SG).

In a number of languages, the length of a given segment is related to the lengths of other segments in the sequence (Lehiste, 1970). For example, in many Scandinavian languages, a long vowel is always followed by a short consonant, and a long consonant is always preceded by a short vowel. In other languages, the quantity degree might be signalled by a complex complementary relationship between multiple neighboring segments, e.g., in Estonian, Livonian, or Inari Sámi (Bye et al., 2009; Lehiste, 1965, 2008; Markus et al., 2012; Türk et al., 2019). For example, in Estonian there exist rather complex complementarity patterns between the intervocalic consonant and the surrounding vowels (Lehiste, 1960). In Inari Sámi, it has been shown that both preceding and following vowels shorten when the intervocalic consonant lengthens (Türk et al., 2019). In the case of North Sámi, a significant complementary relationship between the intervocalic consonant and previous vowel has been suggested by Magga (1984).

A compensatory nature of durational patterns where lengthening of one segment is accompanied by shortening of another may lead to a relatively constant duration of a larger portion of a word. This type of isochrony has been suggested, for example, for Estonian, where the duration of the first bisyllabic foot of a word remains approximately the same despite quantity variation (Eek and Meister, 1997; Krull, 1999).

In most languages with quantity contrast, the opposition is realized by a binary difference in segment durations, i.e., by a difference between short and long vowels and consonants. However, in a few languages in the world, the quantity opposition is realized by a ternary contrast: in addition to short and long segments, there also exist overlong vowels and/or consonants.

There are only a handful of languages where three-way length contrasts have been studied and reported using phonetic measurements. Evidence from a ternary vowel length contrast has been found at least in Estonian (Lehiste, 1965), Livonian (Lehiste, 2008), Shilluk (Remijsen et al., 2019), and Dinka (Remijsen and Gilley, 2008; Remijsen and Manyang, 2009). However, the three-way vowel length contrast systems in Estonian and in the non-Uralic languages, 
Shilluk and Dinka, are fundamentally different: while in Estonian the length contrasts operate over a disyllabic foot, in Dinka they seem to occur in monosyllabic words.

To our knowledge, three distinctive consonant lengths are still only found in some Finnic (Markus et al., 2012) and Sámi languages (see Sec. IB). Importantly, the research tradition of North Sámi quantity seems to be focused on the intervocalic consonant because of the grammatical consonant gradation phenomenon (see Sec. IC).

\section{B. Quantity in the Sámi languages}

Quantity as a suprasegmental feature is present throughout the whole Sámi language continuum, but the systems vary considerably (Bye et al., 2009; Collinder, 1929; Lagercrantz, 1927; Sammallahti, 1998). The languages on the westernmost and easternmost edges of the Sámi speaking areas, South (Hasselbrink, 1981), Kildin (Wilbur, 2007), and Ter Sámi (Itkonen, 1916), are reported to only have a binary length contrast. Many Sámi languages, however, have a ternary quantity opposition, as phonetically attested for Lule (Engstrand, 1987; Fangel-Gustavson et al., 2014), Inari (Bye et al., 2009; Türk et al., 2019), Skolt Sámi (McRobbie-Utasi et al., 2007), as well as for North Sámi language. A possible ternary quantity system has been suggested also for Ume (von Gertten, 2015) and Pite Sámi (Wilbur, 2014), but further research would be required to allow comparisons with the other Sámi languages.

While a number of phonetic studies describe phonetic aspects of quantity contrast realization in several individual North Sámi variants, (see, e.g., Magga, 1984; Baal et al., 2012) for Guovdageaidnu variety of Western Finnmark North Sámi, Sammallahti (1977) for Eastern Eanodat variety also of Western Finnmark North Sámi and Karlsson et al. (2008) for Övre Soppero variant of the Torne Sámi dialect) to our knowledge our work is the first comparative study of quantity realization between related dialects for the Sámi language group, and also the first phonetic description of the Eastern Finnmark dialect quantity system.

\section{The sound system, gradation, and quantity in North Sámi}

The North Sámi vowel system contains six vowels, represented in the orthography with the characters $\boldsymbol{a}, \mathbf{e}, \mathbf{i}, \mathbf{o}$, $\mathbf{u}$, and $\boldsymbol{a}$. The first five are assumed to be realized in the same way in both dialects of Finnmark North Sámi and correspond to phonemes /a, e, i, o, u/. However, the vowel $\boldsymbol{a}^{\prime}$ is pronounced differently in the two dialects. In the Western dialect, it corresponds to the phoneme /a:/, while in the Eastern dialect, exhibiting traces of vowel harmony, the vowel $\boldsymbol{a}$ is in the first syllable of a word pronounced as $/ æ(:) /$ when followed by a front vowel and as /a(:)/ before a vowel /a/, /o/ or /u/ (Kahn and Valijärvi, 2017, pp. 13-14). For a more detailed description of the phoneme system, dialectal differences, and allophonic variation, see Sammallahti (1998).
Note that the different realizations of vowel $\boldsymbol{a}$ are associated with phonemically long sounds. Unlike other vowels, this vowel is reportedly realized as long regardless of consonant quantity (at least in Western dialect, cf. Magga, 1984, p. 114), and has thus often been treated separately from the rest of vowels. Without committing to attribute a phonological status to this phenomenon at this stage (in terms of phonological quantity), we will also be treating this vowel separately from the other vocalic segments. The remaining vowels will be referred to as (phonemically) short. In addition, as further discussed below, the duration of vowels is also expected to vary according to the quantity of intervocalic consonant, and, potentially, as a function of the areal variation.

In North Sámi, most consonants and consonant clusters are involved in gradation, a complex system of phonemic alteration with a strong grammatical function. This is one of the most typical features of North Sámi morphology (Korhonen, 1981) and its most common form is the socalled radical gradation, which occurs around the intervocalic consonant of a disyllabic word root (at the border of the first stressed and second unstressed syllable; North Sámi has fixed lexical stress on the first syllable).

The North Sámi gradation has three categories, with every intervocalic consonant falling in one of the three grades. In most nouns, for example, the uninflected dictionary form (NOM.SG) appears in the overlong (long geminate or cluster) or long (short geminate or cluster) grade, alternating with a shorter grade (short geminate or single consonant) in the inflectional forms (e.g., GEN.SG); for examples, see Table I. Gradation from shorter to longer grade is also possible, but not as common (Kahn and Valijärvi, 2017).

For consonant clusters, the gradation system elicits complex transformations of phonemic characteristics of the consonants, which is outside the scope of this work. Here we concentrate on the common case of ternary length opposition, where the center consists on a single consonant (although some consonants, such as voiced and preaspirated plosives demonstrating qualitative alternations are also left out from this analysis). In this case, gradation affects durational characteristics of the consonant and surrounding segments, primarily manifested in gemination of the consonant. The three grades (or quantities in this case) can thus be referred to as Q1 (short), Q2 (long), or Q3 (overlong), reflecting the phonological length of the consonant.

As illustrated in Table I, the singular nominative and genitive forms work as minimal pairs, differing often only in the length of the intervocalic consonant. Typically, the inflectional gradation of a word root alternates between either Q1-Q2 or Q2-Q3. There are some cases of Q1 vs Q3 opposition, but this applies only in the case of historically contracted nouns or certain kind of word derivations (Sammallahti, 1998).

Consequently, in this work we examine minimal pairs between Q1 vs Q2 and Q2 vs Q3 with the same consonants 
TABLE I. Examples of ternary length contrast for North Sámi consonants. The overlong consonants are marked here with an apostrophe not used in standard orthography.

\begin{tabular}{|c|c|c|}
\hline Q1 (short) & Q2 (long) & Q3 (overlong) \\
\hline nama & namma & \\
\hline \multirow[t]{3}{*}{ "name" GEN.SG } & "name" N OM.SG & \\
\hline & homma & hom'ma \\
\hline & "task" GEN.SG & "task" NOM.SG \\
\hline gili & gilli & \\
\hline \multirow[t]{3}{*}{ "village" GEN.SG } & "village" NOM.SG & \\
\hline & golli & gol'li \\
\hline & "gold" GEN.SG & "gold" NOM.SC \\
\hline & govva & \\
\hline \multirow{3}{*}{ "picture" GEN.SG } & "picture" NOM.SG & \\
\hline & duvvá & duv'vá \\
\hline & "dove" GEN.SG & 'dove' NOM.SG \\
\hline
\end{tabular}

in three different quantities embedded in as similar vowel environment as possible; see Table I for examples.

It is important to note that the modern orthography of North Sámi only distinguishes Q1 from the two longer quantities, but does not mark the difference between Q2 and Q3 for long and overlong geminates (although is often marked in dictionaries with an apostrophe between two consonant letters (see, e.g., Sammallahti, 1994; Nickel and Sammallahti, 2011). The word beassi "birch bark" can thus be read as /peas'si/ NOM.SG or /peassi/ GEN.SG.

\section{Previous research and dialectal differences}

The North Sámi grammars and language learning books give relatively little information on phonetic realization of the quantity contrast. This is possibly due to a limited amount of phonetic research, the non-standardized spoken language, and, presumably the large degree of areal and dialectal variation of phonetic realization of quantity patterns (Sammallahti, 1998). This is especially problematic and interesting in the case of phonetic realization of the opposition between the long and overlong geminates, Q2 and Q3.

For example, the following remark can be found in a North Sámi grammar book by Nickel and Sammallahti (2011, p. 28), translated from Norwegian; the triple consonants marking of Q3 as in original): "[T]he consonants in Q3 are pronounced slightly longer than the consonants in Q2, for example (...) duv'vá /duvvva:/ - duvvát /duvva:ht/ 'a dove - doves.'

On the other hand, in the lecture material based on the Eastern dialect (Aikio and Länsman, 2005) the Q3-Q2 opposition is transcribed by highlighting the difference in the preceding vowel; the previous example would be thus transcribed as "duv'vá /duvva:/ - duvvát /duuvva:ht/."

Note the difference between these two presentations. While the Western dialect examples show the contrast only on the intervocalic consonant's length, in the Eastern dialect the difference between the Q2 and Q3 is marked by a complementary shortening of the first syllable vowel, while the intervocalic consonant remains the same. This suggests an interesting difference between the dialects, described by Sammallahti (1998, pp. 12-13) in the following way:

The Western dialects have retained the phonological opposition between long and short geminates, but the Eastern ones have transferred the opposition to the vowels.

Although the research of North Sámi morphology and phonology has a long tradition (e.g., Nielsen, 1926; Sammallahti, 1977), most descriptions of phonetic realization of the consonant gradation, in particular the comparative ones, such as those cited above, rely on impressions and have never been experimentally tested.

To date, the most extensive phonetic investigation regarding the quantity phenomena in this language is presented by Magga (1984), who investigated the durational patterns in Guovdageaidnu variety of the Western Finnmark North Sámi. Magga recorded and analyzed material from three native speakers, altogether 5040 bisyllabic target words (containing all possible grade alternation patterns and vowel environments in North Sámi).

One of main aims of his work was to evaluate the claim by Sammallahti (1977) (also maintained by Aikio and Länsman, 2005, in a much later account) that, under gradation, the first syllable vowels and the second syllable onset consonant exhibit three different lengths, and the second syllable vowel two distinct durations. Some of the most important findings from Magga (1984) were that in the Guovdageaidnu variety, vowels might show a binary rather than ternary durational contrast, and that the durations of the segments in the disyllabic target words robustly interact with each other. In particular, the lengthening of the intervocalic consonant is to some degree compensated by shortening of the previous vowel. This can be seen in Table II with the mean durations of second syllable consonants and the first syllable vowels (short and $\boldsymbol{a}$, see Sec. IC) in three quantity degrees calculated from the values reported by Magga (1984).

These findings are partly corroborated in our own earlier paper presenting an analysis of a subset of the speech material analyzed here (Hiovain and Šimko, 2019). In addition to dialectal differences, that work also investigates the majority language influence on the phonetic realization of quantity contrast in North Sámi and suggests that the Q2-Q3 opposition is significantly more robust for the North Sámi speakers from Finland (mostly Eastern dialect speakers in the data) compared to the participants from Norway (mostly speakers of Western dialect in the data).

TABLE II. Mean durations (across all three speakers) of the first syllable vowel (short or $\boldsymbol{a}$ ) and the following consonant calculated form results reported by (Magga, 1984).

\begin{tabular}{lccc}
\hline \hline & \multicolumn{3}{c}{ 1st syllable vowel } \\
\cline { 2 - 4 } & Short & \multicolumn{1}{c}{} & Intervocalic consonant \\
\hline Q1 & $126 \mathrm{~ms}$ & $254 \mathrm{~ms}$ & $123 \mathrm{~ms}$ \\
Q2 & $94 \mathrm{~ms}$ & $178 \mathrm{~ms}$ & $272 \mathrm{~ms}$ \\
Q3 & $90 \mathrm{~ms}$ & $154 \mathrm{~ms}$ & $351 \mathrm{~ms}$ \\
\hline \hline
\end{tabular}




\section{E. Research aims and hypotheses}

Inspired by the challenges introduced above, the aim of this work is divided to two main tasks: (1) providing a phonetic description of the Finnmark North Sámi quantity patterns in terms of segmental duration and (2) evaluating potential differences in this realization between the Eastern and Western dialect.

Regarding the aim (1), we evaluate the hypothesis that the domain of quantity contrasting in North Sámi is a foot (the first two syllables of the word), in particular, an inverse complementary relationship between the duration of the intervocalic consonant (increasing from Q1 to Q3) and duration of the first syllable vowel (decreasing from Q1 to Q3).

Given the complementarity, we also compare the quantity realization in terms of a ratio between the durations of these two segments, assuming that relative durations might signal the contrast more robustly than durations of individual segments. Unlike the "raw" durational measurements, the ratios between durations of intervals are not sensitive to speaking rate and other tempo adjustments. Because of this, it is plausible that it is in fact this type of relational measure, rather than individual durations, that are perceptually more robust and therefore used by language users to signal required contrasts (cf. Lehiste, 1960).

We also examine if this complementarity is robust enough to eliminate overall duration differences of the foot between the three quantity degrees (a foot isochrony hypothesis).

Regarding the dialectal differences-aim (2)-we evaluate a claim cited above (Sammallahti, 1998) of Eastern dialect speakers realizing the ternary contrast primarily using vowel duration and the Western dialect speakers by consonant duration differences. We also investigate the potential effect of the reported (durational and qualitative) differences in production of the vowel $\boldsymbol{a}$ between the dialects.

We will use the considerable range of speaker ages in our data to look at the potential age effects on signalling the contrast between Q2 and Q3.

\section{DATA COLLECTION AND METHODS}

\section{A. Speakers}

The data were collected from ten native speakers of the Western and Eastern dialects of Finnmark North Sámi (see Table III for the overview of participants, and Fig. 2 for geographical distribution of their places of origin). The speakers' age range was 24-64 for the four Eastern dialect speakers and 24-63 for the six Western dialect ones.

As seen in Table III, the analysed data set is somewhat unbalanced. While we assume that the mixed effect models used for data analysis help to mitigate this, these biases might still have an influence on the results.

Six speakers were recorded during two data collection trips made in 2018 to Anár (Finland) and Guovdageaidnu (Norway), both located in traditional Sámi (speaking) areas.
TABLE III. An overview of the speakers whose recordings are analyzed here, their sex and place of origin (cf. Fig. 2). W1-W6 are Western dialect speakers, E1-E4 Eastern dialect speakers. The Tokens column indicates the number of tokens for each speaker.

\begin{tabular}{lcccc}
\hline \hline Id & Sex & Place of Origin & Tokens & Birth decade \\
\hline W1 & M & Guovdageaidnu (Nor) & 263 & $1990 \mathrm{~s}$ \\
W2 & F & Guovdageaidnu (Nor) & 171 & $1980 \mathrm{~s}$ \\
W3 & F & Guovdageaidnu (Nor) & 171 & $1970 \mathrm{~s}$ \\
W4 & F & Guovdageaidnu (Nor) & 171 & $1950 \mathrm{~s}$ \\
W5 & M & Guovdageaidnu (Nor) & 171 & $1990 \mathrm{~s}$ \\
W6 & F & Vuohčču (Fin) & 263 & $1990 \mathrm{~s}$ \\
E1 & F & Anár (Fin) & 265 & $1990 \mathrm{~s}$ \\
E2 & F & Ohcejohka (Fin) & 318 & $1980 \mathrm{~s}$ \\
E3 & M & Kárášjohka (Nor) & 114 & $1950 \mathrm{~s}$ \\
E4 & M & Anár (Fin) & 53 & $1960 \mathrm{~s}$ \\
\hline \hline
\end{tabular}

The recordings were made in small quiet office rooms with a Zoom $\mathrm{H} 2 \mathrm{n}$ hand-held recorder. The remaining four speakers were recorded in a sound treated room at the Phonetics studio of the University of Helsinki in 2017 using an AKG 4000B condenser microphone (while Helsinki is not in a traditional Sámi speaking area, there are relatively big and active Sámi communities there). The sampling rate for both recording devices was set to $44.1 \mathrm{kHz}$ with 16 bits per sample.

The instructions were given mainly in North Sámi and Finnish, and the speakers filled in a consent form before the recording sessions. Information about their places of origin and residence, profession, and their language and dialectal backgrounds was also collected. All participants stated that they have learned North Sámi as their first language.

Due to the sociolinguistic circumstances of North Sámi (see Aikio et al., 2015), most speakers are bilingualincluding all participants in this study-meaning that they have learned North Sámi at home, and Finnish or Norwegian at a very young age in kindergarten or school.

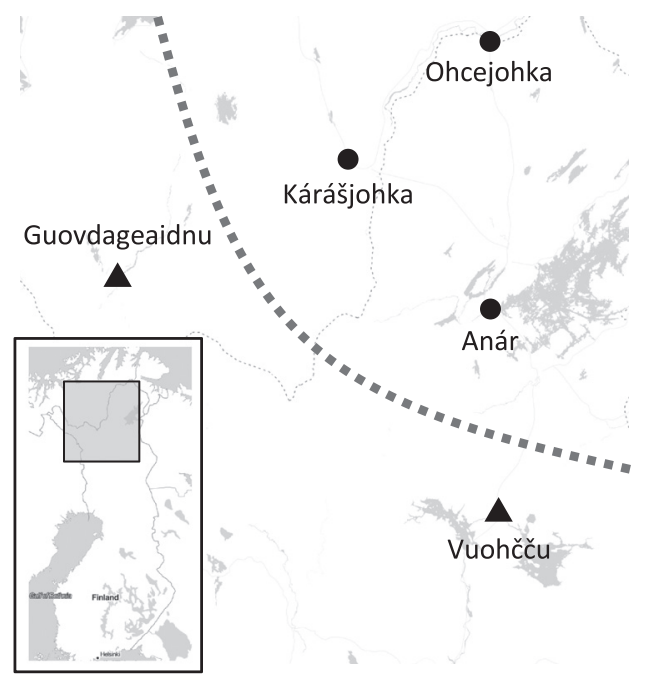

FIG. 2. Map of the Finnmark North Sámi speaking area. The triangles mark the Western dialect sites and circles the Eastern dialect sites. The dashed line indicates approximate geographical divide between the dialects. 
Nearly all speakers were using North Sámi in their work (teachers or translators) and/or had studied the language at the University level. All participants were thus proficient North Sámi speakers and there were no discernible differences in language competence among them.

As can be seen in Table III, six of the speakers recorded for this experiment were Sámi-Norwegian bilinguals, and four were Sámi-Finnish bilinguals. Six of the subjects represented the Western Finnmark dialect, and four of them had an Eastern Finnmark dialectal background. Mostly the speakers from Norway were representing the Western dialect of Finnmark North Sámi, except for one who was an Eastern dialect speaker. Accordingly, all except one speaker from Finland were Eastern dialect speakers.

\section{B. Material}

Each of 55 analyzed target words is of the form (C1)V1C2V2(C3). The intervocalic consonant C2 was one of the following set $/ d, 1, \mathrm{~m}, \mathrm{n}, \mathrm{y}, \mathrm{s}, \mathrm{v} /$ and in all analyzed tokens the vowels V1 and V2 were monophthongs. Given potential durational differences (see Sec. ID), we distinguish between two types of the first syllable vowel V1: $\boldsymbol{a}$ vs (the remaining) short vowels. This division of the vowels allows systematic analysis and dialectal comparison of the realization of the V1 lengthening as related to the following consonant $\mathrm{C} 2$.

The target words were read in a sentence-medial position, embedded in one of four different carrier sentences, for example:

\section{Mun dajan "duvvá" dutnje ođđasit \\ "I say 'a dove' to you again."}

Each target word was presented 1-6 times (depending on a speaker), in a randomized order. The entire carrier sentence was read aloud, but only the target word was analyzed.

The North Sámi orthography does not distinguish between short or long geminates (Q2 and Q3); the proper form of the intervocalic consonant needs to be inferred from the grammatical form of the word. As the grammatical status is ambiguous in citation form, quantity Q3 was marked in the presentation by an apostrophe, as in the last column in Table I. The speakers were informed about the meaning of the additional apostrophe and as nearly all of the speakers were professional and native users of North Sámi, they most likely knew the meaning already since it is used in many North Sámi dictionaries, e.g., Sammallahti (1994).

Table IV summarizes the distribution of analyzed tokens by quantity and V1 type; the distribution of recorded tokens by speakers can be found in Table III. Note that some of the recorded tokens were discarded from the analysis due to misreadings or misunderstandings of the target words because of the orthographical differences between the dialects.

There were some challenges faced during the speech recordings caused by the dialectal differences of the
TABLE IV. The distribution of the analyzed tokens for different vowel types and quantity degrees.

\begin{tabular}{lccc}
\hline \hline & V1 short & V1 á & Overall \\
\hline Q1 & 338 & 298 & 636 \\
Q2 & 254 & 298 & 552 \\
Q3 & 500 & 134 & 634 \\
Total & 1092 & 730 & 1822 \\
\hline \hline
\end{tabular}

Western and Eastern dialects, namely, in presenting the carrier sentences to the speakers in their standard orthographic form. Generally, the most used North Sámi dictionary by Sammallahti (1994) was used to find and check the orthography of the target words. Some of the target words or part of the carrier sentence had to be altered depending on the dialect of the speaker.

Because many of the speakers were "professional" users of the North Sámi language-teachers, presenters, translators-many interruptions or repetitions were made during the recordings and the correct pronunciation was discussed. In these cases, the speakers were told to pronounce the carrier sentence as they found most suitable in their own dialect. Only the last of these productions was taken into account in the analyses.

The contributing factor to these challenges might also be the fact that the current orthography of North Sámi is relatively new. It was established only in 1978 (Kulonen et al., 2005) and there are still some irregularities in written North Sámi. It is also notable that the standard written language is based primarily on the Western dialect, with incorporation of some features of the Eastern dialect (Kahn and Valijärvi, 2017). Finally, the majority languages, Norwegian and Finnish, differ from each other substantially in written conventions which might also have an impact on this issue.

\section{Methods}

The target words in carrier sentences were presented one by one as a slide show in a randomized order by using a customized Praat script (Boersma, 2002). The speakers read the entire sentence, and were encouraged to say it as naturally as possible. Subsequently, the recording were automatically transcribed and segmented on word and phoneme levels using WebMAUS Basic forced-aligner (Kisler et al., 2017; Schiel, 1999). The forced alignments and segmentations of the target words were then manually adjusted by listening to the audio signal, and looking at Praat spectrogram (with $F 0$ and formants visible) and oscillogram pictures of the target words. The segment borders were decided based on standard guidelines of segmentation presented in, e.g., Ladefoged (2003), and durations of segments was extracted.

Subsequently, the influences of quantity degree, speaker's dialect, and V1 type on segment durations (and two derived measures) were statistically evaluated. Namely, the effects on durations of the first four segments in the token words (comprising the first foot), on the duration of the entire foot as well as on the ratios between the $\mathrm{C} 2$ and $\mathrm{V} 1$ 
durations have been modelled by fitting mixed effect models with ( $\log _{2}$ of) these measures as dependent variables and the phonological quantity (QTY), dialectal group (DIAL), and $\mathrm{V} 1$ type $(\mathrm{V} 1 \mathrm{~T})$ as fixed independent factors, with interactions. The intercepts and slopes of QTY and V1T for speaker as well as intercepts for tokens were treated as random factors in all fitted models. Logarithmic rather than linear durations were used in order to correct for the non-normality of durational measure distributions.

For each fitted model, we report the results of an analysis of variance (ANOVA) analysis of the main effects (Table V)

TABLE V. Type III Analysis of Variance (using Satterthwaite's method) for the fitted mixed effect models. The dependent variables are indicated in bold. For the summary of post-hoc analysis, see Table VI $(* * *<0.001<* *<0.01<*<0.05)$.

\begin{tabular}{|c|c|c|c|c|c|}
\hline & MeanSq & NumDF & $D e n D F$ & $F$-val & $p$-val \\
\hline \multicolumn{6}{|l|}{ C1 duration } \\
\hline Qту & 0.13 & 2 & 50.99 & 0.67 & 0.517 \\
\hline DiAL & 4.12 & 1 & 8.37 & 21.51 & $0.001^{* *}$ \\
\hline $\mathrm{V} 1 \mathrm{~T}$ & 0.13 & 1 & 52.28 & 0.65 & 0.422 \\
\hline QTY:DiAL & 0.03 & 2 & 13.57 & 0.16 & 0.855 \\
\hline Qту::V1T & 0.04 & 2 & 48.85 & 0.21 & 0.811 \\
\hline DIAL:V1T & 0.07 & 1 & 10.54 & 0.37 & 0.556 \\
\hline QTY:DiAL:V1T & 0.03 & 2 & 1672.03 & 0.16 & 0.850 \\
\hline \multicolumn{6}{|l|}{ V1 duration } \\
\hline QTY & 0.84 & 2 & 49.98 & 15.63 & $0.000^{* * * *}$ \\
\hline DiAL & 0.04 & 1 & 7.94 & 0.66 & 0.439 \\
\hline V1t & 1.39 & 1 & 52.74 & 25.77 & $0.000^{* * *}$ \\
\hline QTy:Dial & 0.32 & 2 & 9.58 & 5.84 & $0.022^{*}$ \\
\hline Qту::V1т & 0 & 2 & 49.46 & 0.02 & 0.98 \\
\hline DIAL:V1T & 2.99 & 1 & 8.06 & 55.45 & $0.000^{* * * *}$ \\
\hline QTY:DiAL:V1T & 0.01 & 2 & 1736.97 & 0.13 & 0.876 \\
\hline \multicolumn{6}{|l|}{ C2 duration } \\
\hline QTY & 3.38 & 2 & 54.51 & 86.62 & $0.000^{* * * *}$ \\
\hline DiAL & 0.01 & 1 & 8 & 0.3 & 0.602 \\
\hline V1t & 0 & 1 & 54.35 & 0.02 & 0.893 \\
\hline QTY:DiAL & 0.11 & 2 & 8.46 & 2.72 & 0.122 \\
\hline Qту::V1т & 0 & 2 & 51.16 & 0.01 & 0.988 \\
\hline DIAL:V1T & 0.04 & 1 & 6.81 & 1.15 & 0.321 \\
\hline QTY:Dial:V1T & 0.91 & 2 & 1733.21 & 23.41 & $0.000^{* * *}$ \\
\hline \multicolumn{6}{|c|}{ C2:V1 duration ratio } \\
\hline QTY & 6.29 & 2 & 51.94 & 59.17 & $0.000^{* * *}$ \\
\hline DiAL & 0.22 & 1 & 8.01 & 2.05 & 0.19 \\
\hline V1t & 1.09 & 1 & 53.81 & 10.23 & $0.002^{* *}$ \\
\hline Qty:Dial & 1.07 & 2 & 8.82 & 10.11 & $0.005^{* *}$ \\
\hline Qту::V1т & 0 & 2 & 50.66 & 0.02 & 0.977 \\
\hline DIAL:V1T & 9.49 & 1 & 7.57 & 89.38 & $0.000^{* * * *}$ \\
\hline QTY:DiAL:V1T & 0.77 & 2 & 1731.98 & 7.25 & $0.001^{* * * *}$ \\
\hline \multicolumn{6}{|l|}{ Foot duration } \\
\hline QTY & 0.23 & 2 & 51.45 & 11.2 & $0.000^{* * * *}$ \\
\hline DiAL & 0.01 & 1 & 7.97 & 0.31 & 0.594 \\
\hline V1t & 0.2 & 1 & 50.71 & 9.94 & $0.003^{* *}$ \\
\hline QTY:DiAL & 0.13 & 2 & 8.86 & 6.13 & $0.021^{*}$ \\
\hline Qту::V1т & 0.02 & 2 & 47.46 & 0.96 & 0.389 \\
\hline DiAL:V1T & 0.42 & 1 & 7.53 & 20.23 & $0.002^{* * *}$ \\
\hline QTY:Dial:V1T & 0.19 & 2 & 1661.14 & 9.21 & $0.000^{* * * *}$ \\
\hline
\end{tabular}

as well as the results of post hoc analysis of differences of interest evaluated using multiple comparison Tukey honest significant difference (HSD) test. For each model, we run a full set of comparisons with all possible cases differing in the value of precisely one independent factor, see Table VI. In addition, the comparisons of the Q2-Q3 difference between dialect groups (essentially, the interaction between the dialect and quantity effects) in both V1 type contexts were included; they are not listed in the table for spatial reasons.

The statistical analyses were performed using RStudio (R Core Team, 2019) with linear mixed-effect model packages lme4 (Bates et al., 2015) and multcomp (Hothorn et al., 2008).

\section{RESULTS}

\section{A. Effects of quantity, dialect, and V1 type}

The left hand side of Fig. 3 depicts the estimates of durations of the first four segments comprising the foot (recalculated to milliseconds from the logarithmic scale) obtained from the models with the segment durations as dependent variables. Each estimate was calculated by recentering the appropriate model, i.e., by selecting the relevant levels as bases of the independent factors. In what follows, we report the results obtained from these fits, starting with the effects on the segments $\mathrm{C} 2$ and V1 that primarily participate in signalling quantity contrast in North Sámi.

\section{C2 duration}

As shown by the ANOVA analysis summarized in Table V, the quantity (QTY) is the only main effect significantly influencing the $\mathrm{C} 2$ duration, alongside the three-way interaction between quantity, dialectal group, and V1 type.

The results of post hoc analysis for this duration, summarized in the 5th column in Table VI, reveal that the differences in $\mathrm{C} 2$ duration is primarily accounted for by the contrast between Q1 and Q2, with $\mathrm{C} 2$ estimated to be between $\left(2^{1.019}=\right) 2.03$ and $\left(2^{1.219}=\right) 2.33$ times longer in the latter than in the former (the reported estimates are differences between $\log _{2}$ durations, i.e., $\log _{2}$ duration ratios). These differences are significant for all four dialect group-V1 type combinations (the rows $2-5$ in Table VI). The durational difference for Q2-Q3 contrast is only significant for Eastern dialect speakers and only in the context of a short preceding vowel (row 7).

\section{V1 duration}

Quantity degree and, as expected, V1 type are both significant main effects for V1 duration. Interactions between dialect group and quantity, as well as dialect group and V1 type, are also significant (see Table V).

As shown by the post hoc analysis (column 4 in Table VI), V1 is significantly shorter in Q2 than in Q1 only for the Eastern dialect material (rows 2,3). In these two quantities, the short V1 is produced significantly shorter by the Western than by the Eastern dialect 
TABLE VI. The results of post hoc analysis of relevant comparisons for various subsets obtained from the fitted mixed effect models using multiple comparison Tukey HSD test. Effect sizes (in $\log _{2}$ of duration for durational measures; difference of $\log _{2}$ of durations for ratios) and their significances $(* * *<0.001<* *<0.01<*<0.05)$ are shown.

\begin{tabular}{|c|c|c|c|c|c|c|c|}
\hline Comparison & Subset & $\mathrm{C} 1$ duration & V1 duration & $\mathrm{C} 2$ duration & V2 duration & $\mathrm{C} 2$ :V1 ratio & Foot duration \\
\hline \multirow[t]{4}{*}{ Q2-Q1 } & East \& á & -0.183 & $-0.526^{* *}$ & $1.219^{* * *}$ & 0.074 & $1.741^{* * *}$ & 0.075 \\
\hline & East \& short & -0.047 & $-0.501^{* *}$ & $1.044^{* * *}$ & 0.071 & $1.540^{* * * *}$ & 0.122 \\
\hline & West \& á & -0.188 & -0.376 & $1.019^{* * *}$ & 0.132 & $1.396^{* * *}$ & 0.101 \\
\hline & West \& short & -0.064 & -0.333 & $1.146^{* * *}$ & -0.020 & $1.478^{* * *}$ & $0.276^{* * *}$ \\
\hline \multirow[t]{4}{*}{ Q3-Q2 } & East \& $\dot{a}$ & 0.210 & -0.235 & 0.350 & 0.097 & 0.583 & 0.119 \\
\hline & East \& short & 0.047 & -0.272 & $0.397^{*}$ & -0.034 & $0.672^{*}$ & 0.056 \\
\hline & West \& á & 0.141 & -0.057 & 0.240 & 0.103 & 0.292 & 0.096 \\
\hline & West \& short & 0.042 & -0.081 & 0.257 & -0.062 & 0.337 & 0.049 \\
\hline \multirow[t]{6}{*}{ West-East } & Q1\& á & -0.217 & 0.069 & 0.231 & -0.181 & 0.158 & -0.011 \\
\hline & Q2 \& á & $-0.222^{*}$ & 0.220 & 0.031 & -0.123 & -0.186 & 0.016 \\
\hline & Q3 \& á & -0.291 & 0.398 & -0.078 & -0.117 & $-0.478^{*}$ & -0.007 \\
\hline & Q1 \& short & $-0.275^{* *}$ & $-0.571^{* * *}$ & 0.084 & 0.028 & $0.658^{* * *}$ & -0.239 \\
\hline & Q2 \& short & $-0.293^{* * *}$ & $-0.403^{* *}$ & 0.187 & -0.062 & $0.595^{*}$ & -0.085 \\
\hline & Q3 \& short & $-0.297^{* *}$ & -0.212 & 0.047 & -0.090 & 0.261 & -0.092 \\
\hline \multirow[t]{6}{*}{ short-á } & Q1 \& East & -0.099 & -0.157 & 0.091 & 0.080 & 0.241 & -0.065 \\
\hline & Q2 \& East & 0.038 & -0.131 & -0.084 & 0.077 & 0.041 & -0.018 \\
\hline & Q3 \& East & -0.125 & -0.169 & -0.038 & -0.054 & 0.129 & -0.081 \\
\hline & Q1 \& West & -0.157 & $-0.797^{* * *}$ & -0.056 & 0.289 & $0.741^{* *}$ & $-0.293^{* * *}$ \\
\hline & Q2 \& West & -0.033 & $-0.754^{* * *}$ & 0.071 & 0.138 & $0.823^{* *}$ & -0.118 \\
\hline & Q3 \& West & -0.132 & $-0.778^{*}$ & 0.087 & -0.027 & 0.868 & -0.165 \\
\hline
\end{tabular}

speakers (rows 13,14). For the Western dialect speakers, the short vowels are significantly shorter than the vowel $\dot{a}$ in all quantity degrees (rows 19-21); the difference between these vowel types is, however, not significant in the Eastern dialect material.

Interestingly, although the difference in V1 duration between Q2 and Q3 is not significant for any dialect-V1 type combination (rows 6-9), for short V1s, the difference is significantly more pronounced by the Eastern than by the Western dialect speakers $(p=0.018$; the additional post hoc comparison not listed in Table VI, see Sec. II C).

\section{C2:V1 duration ratio}

All main effects and interactions significant for either $\mathrm{C} 2$ duration or $\mathrm{V} 1$ duration are also significant for the ratio between the durations, shown in the right hand panel in Fig. 3.

Looking at column 7 in Table VI, the ratios are robustly and significantly greater in Q2 than in Q1. The ratio is significantly greater in Q3 compared to Q2, but only in the Eastern dialect material in the short vowel context. For Western dialect the ratios are significantly greater for short V1s than for $\boldsymbol{a}$ in Q1 and Q2. Also, for the short V1s, the
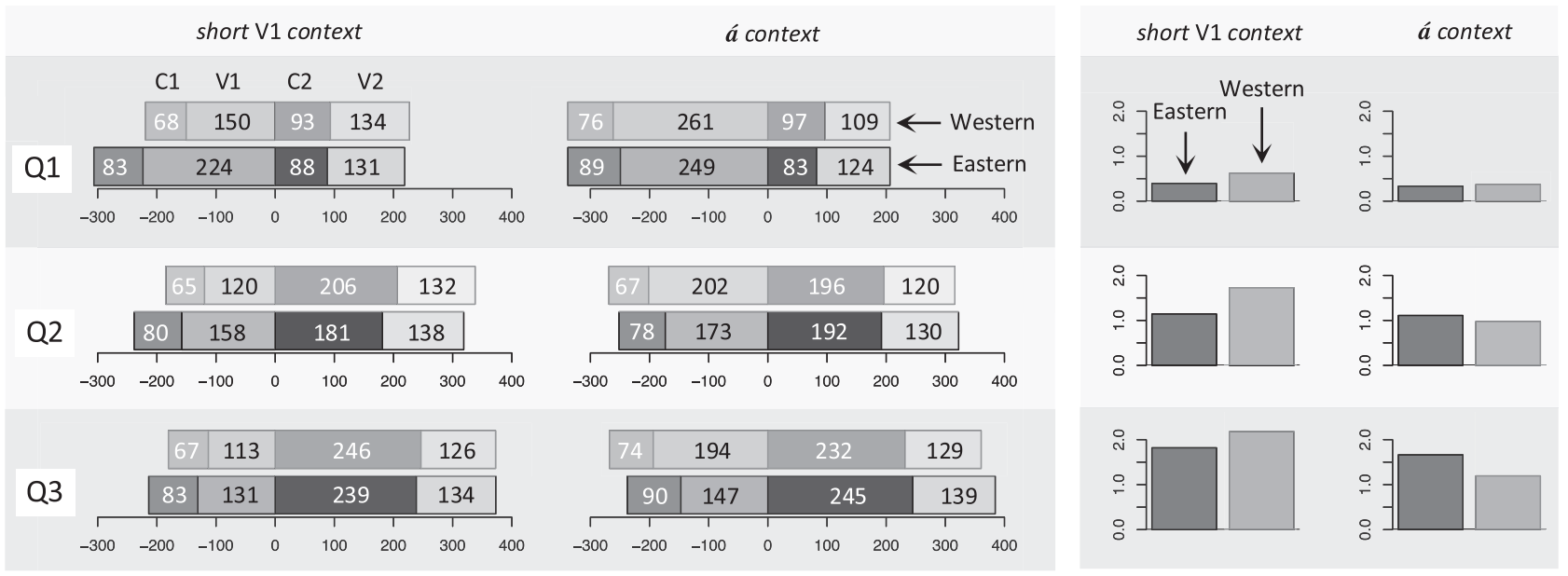

FIG. 3. Estimates of segment durations (left) and C2:V1 ratios (right) for the analyzed material, for the three quantity degrees, two V1 type contexts, and both dialects. The estimates are obtained from the mixed effect models with a given duration or ratio as a dependent variable. The segment durations (in ms) are recalculated from $\log _{2}$ scale used for modelling. The time intervals are aligned with respect to the onset of $\mathrm{C} 2$. 
ratios are significantly greater in the Western dialect than in the Eastern one in Q1 and Q2, and significantly smaller in the Western than Eastern material for the vowel $\boldsymbol{a}$ in Q3.

Interestingly, the differences between ratios for Q3 and for Q2 are greater for Eastern than for Western dialects in both V1 contexts ( $p<0.001$ for short V1 type; $p=0.018$ for a), indicating that in the Eastern dialect, the contrast between Q2 and Q3 is realized more robustly than in Western one.

\section{Durations of $C 1$ and V2}

As can be seen in Fig. 3, the durations of two remaining segments in the first foot differ minimally between quantity degrees, dialects, and the V1 type contexts. In fact, no differences in the V2 duration along these three factors are significant in our dataset (the ANOVA results for this measure are omitted in Table $\mathrm{V}$ for space reasons).

For $\mathrm{C} 1$, the only significant main effect is that of dialect. As shown by post hoc analysis (column 3 in Table VI), the word initial consonant is indeed produced significantly shorter in Western dialect than in the Eastern one when followed by the short consonant, and when followed by á in Q2.

\section{Entire foot duration}

Figure 3 suggests that the compensatory effects, in particular between the durations of $\mathrm{V} 1$ and $\mathrm{C} 2$, result in a relatively stable duration of the entire foot (the first two syllables of the words our material) across all conditions. Surprisingly, the ANOVA analysis found that this duration is significantly influenced by the main effects of quantity, V1 type, as well as the interactions between quantity and dialect, dialect and V1 type, and the three-way interaction. The post hoc analysis, however, reveals (column 8 in Table VI) that the source of these effects is the fact that the foot is produced as significantly shorter in Western dialect in Q1 with the short V1 than in any other condition.

\section{B. Speaker age as an effect to the production of quantity}

The results so far show a relatively weak degree to which the contrast between Q2 and Q3 is signalled in terms of duration of both consonant $\mathrm{C} 2$ and the preceding vowel (V1) as well as the ratio between these durations. In order to investigate the potential development of realization of this quantity contrast, we calculated the difference between means of $\log _{2}$ of durations of $\mathrm{C} 2$ (and V2, respectively) in Q3 and in Q2 for each individual speaker and for each V1 type separately (as a difference of logarithmic measures this is in essence a ratio of mean durations in Q3 vs Q2, and normalized for potential differences in speech tempo.)

In Fig. 4, these $\log _{2}$ Q3:Q2 ratios are plotted against the year of birth of each speaker, for V1 at the top and C2 at the bottom, and for short V1 in black and $\boldsymbol{a}$ in grey. The lines indicate the linear fits of regressions of the difference values against the year of birth, separately for the two V1
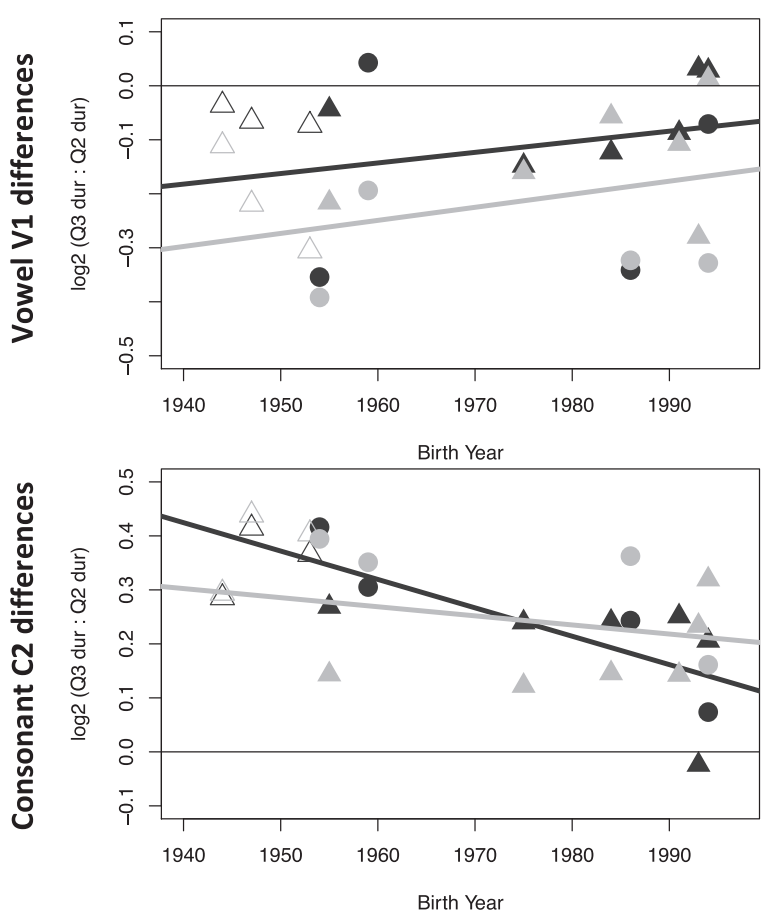

FIG. 4. Relationship between the age of speakers and the degree ( $\log _{2}$-ratio) to which average duration of V1 (top) and C2 (bottom) differ between Q2 and Q3. The Western dialect speakers are marked with triangles and Eastern dialect ones with circles. Full markers show the data analyzed here, empty ones the estimates for speakers analyzed by Magga (1984). The darker and lighter symbols distinguish between the short V1s and $\boldsymbol{a}$, respectively.

types. Estimates calculated from the results of Magga (1984) are also shown in the figure for comparison. While we have not included these data points in the regression models reported below (as the material was collected using different elicitation method), they generally agree with the trends revealed in our own data.

As can be seen, all four regression lines slope towards zero difference value, i.e., no durational contrast, for younger speakers (upwards for V1 and downwards for C2). In fact, this trend is only significant for duration differences for $\mathrm{C} 2$ in short V1 context; the slope is significantly negative ( $p=0.019$ ), and $\mathrm{R}$-squared for the fit is 0.46 (for the remaining three fits the slope is not significant and R-squared values are negligible).

The plot for C2 durations after short V1 shows an interesting pattern. The Q3-Q2 difference is rather large for the oldest participants born around and before 1960, in particular the speakers of Eastern dialect. For most of the remaining speakers, the difference remains moderate, apart from two of the youngest participants (born in the early-mid 1990s) who seem to realize the contrast minimally or not at all.

\section{DISCUSSION AND CONCLUSIONS}

Our data show that the contrast between Q1 and Q2 is maintained for both dialects and in both vocalic (V1) contexts. This contrast is robustly manifested in particular in lengthening of the intervocalic consonant $\mathrm{C} 2$, with the 
geminates in Q2 being approximately twice as long as the singletons in Q1. For Eastern dialect speakers the contrast is also signalled by considerable compensatory shortening of the previous vowel.

The two vowel types, presumably "long" á vs other, "short" vowels are only separated in the Western dialect, where $\boldsymbol{a}$ is longer than other vowels in every quantity. Based on our data, the Eastern dialect speakers do not seem to distinguish this vowel from the others durationally, in any context considered here. Our results thus point towards a tentative conclusion that while there is a genuine phonological length distinction for vowels in the West dialect, in the East, such phonological length contrast does not exist, and the vowel durational changes are limited to compensatory consequences of signalling quantity contrast.

Our results also indicate other considerable differences in the way the two dialects signal the quantity contrast, in particular the difference between Q2 and Q3. The Eastern dialect speakers use durations of $\mathrm{C} 2$, at least when $\mathrm{V} 1$ is a short vowel. The shortening of previous short vowel Q3 compared to Q2 is significantly more robust for the speakers of this dialect than for the Western dialect ones. In fact, for the Western dialect we did not find any durational characteristic that would be significantly correlated with Q2-Q3 contrast, contradicting the earlier claim of Sammallahti (1998) cited in Sec. ID.

Against the expectations, the ratio between the durations of $\mathrm{C} 2$ and $\mathrm{V} 1$ does not seem to signal the quantity contrast qualitatively more robustly than the individual durations between them. At the same time, the dialects significantly differ in the degree to which the ratios distinguish Q3 and Q2, providing further support to the possibility of no remaining systematic difference between the two longer quantity degrees in Western dialect, at least in terms of duration.

The effects of quantity oppositions, at least in terms of duration, seem to be limited to variation in duration of the first syllable vowel and the second syllable consonant. As the effects span the first two syllables of the word, we can conclude the domain of quantity contrast is the first foot, even though there might not be any systematic durational correlates for the other segments in the foot. Interestingly, with the foot duration (mostly) not influenced by the quantity degree, our results point towards a "perfect" compensatory nature of the interplay between $\mathrm{C} 2$ and V1 durations, showing evidence of foot isochrony.

Our aim was to verify and document differences in phonetic realization of quantity opposition in two dialects of Finnmark North Sámi. Figure 5 plots the estimates of durations of V1 against $\mathrm{C} 2$ (the same estimates as used in Fig. 3) for the three quantity degrees and the two V1 types. When grouping together patterns that are not significantly different from each other (enclosed in ellipses in the figure), in either dimension, we obtain two very different quantity systems for the two dialects.

The Eastern dialect shows a three-way contrast, reflecting the ternary gradation system of North Sámi. The

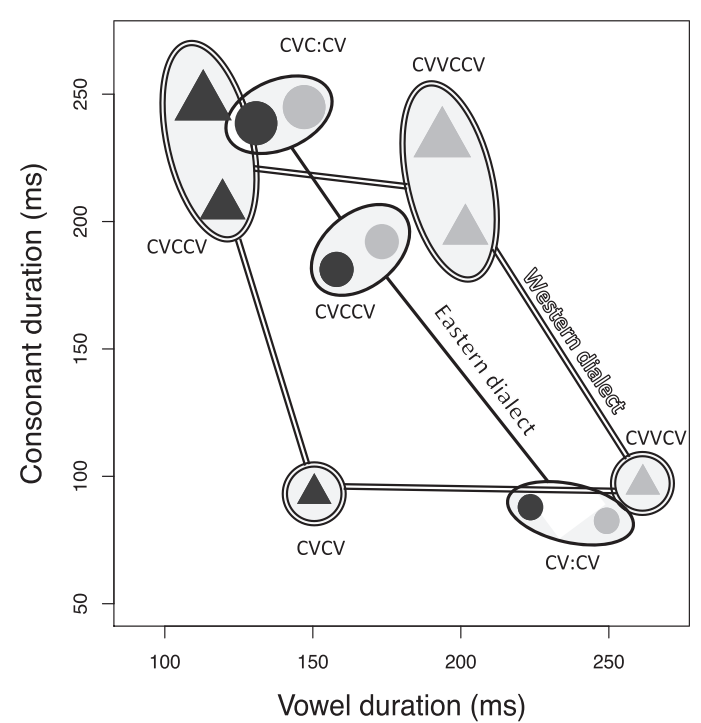

FIG. 5. Overview of the quantity systems of Eastern and Western dialects. C2 duration estimates for the three quantity degress (size of the symbol), two dialects (Western with triangles, Eastern with circles) and V1 type (short in black, $\boldsymbol{a}$ in grey) plotted against the corresponding V1 duration estimate. Hypothetical foot structures are also indicated (doubling a letter indicating phonological contrast while a colon standing for a compensatory effect).

durational contrast between "short" and "long" vowels is not realized for this dialect, but the same opposition is presumably signalled by vowel quality instead. Western dialect, however, seems to have adopted a $2 \times 2$ quantity system, with all combinations resulting form a durational binary contrast for vowels (albeit limited to $\boldsymbol{a}-\boldsymbol{a}$ pair and cosignalled by some quality differences), and an "atrophied" two-way contrast for consonants.

While confirming differences between the dialects, our results do not fully agree with the older observations outlined in Sec. ID. Rather than using the first syllable vowel duration as the primary way to signal the three-way quantity opposition, as suggested by Sammallahti (1998), the group of the Eastern dialect speakers analyzed here realize the contrast by consonant duration differences. Our Western dialect speakers, expected to "retain" the opposition between long and short geminates, actually realize this

TABLE VII. Ratios of a overlong geminate to a long geminate in different Sámi languages as reported in literature; at the bottom are the ratio estimates from this work. When two numbers are reported, the first refers to a short 1st syllable vowel and the second to a "long" one.

\begin{tabular}{lc}
\hline \hline Language & Q3:Q2 ratio \\
\hline Inari Sámi (Bye et al., 2009) & 1.33 \\
Inari Sámi (Türk et al., 2019) & $1.82 / 1.00$ \\
North Sámi (Western) (Baal et al., 2012) & 1.22 \\
North Sámi (Western) (Magga, 1984) & 1.29 \\
Skolt Sámi (McRobbie-Utasi et al., 2007) & 1.53 \\
Lule Sámi (Fangel-Gustavson et al., 2014) & 1.50 \\
Western dialect & $1.19 / 1.18$ \\
Eastern dialect & $1.32 / 1.28$ \\
\hline \hline
\end{tabular}


contrast, if at all, to a measurably smaller degree than their Eastern dialect counterparts.

Comparing ternary quantity of consonants among the Sámi languages is challenging due to the great variability in the languages, and it would deserve a separate research contribution. Nevertheless, some Q3:Q2 consonant ratios, calculated from duration measurements, have been reported in Türk et al. (2019) for Inari, Skolt, North, and Lule Sámi. These ratios and the ratios calculated from the duration estimates (see Fig. 3 from our data are summarized in Table VII). The numbers further highlight the difference between the dialects, with the ratios for the Eastern dialect comparable with those of Inari Sámi and the older measurements for the Western dialect of North Sámi, and considerably lower ratios obtained from our data for Western dialect.

This tendency is compatible with our other finding of the significant trend towards less robust differences between segment durations in Q2 and Q3 for younger speakers. Our results thus indicate an increasing instability of the ternary length contrast in Finnmark North Sámi, and likely document an ongoing language change. The direction of the change is broadly consistent with the claim of McRobbieUtasi et al. (2007) that ternary contrasts are rare but also unstable and transitory and that they might be shifting towards binary distinction that is presumably "easier" for language users.

In addition to the postulated intrinsic complexity of the ternary contrast, there might also be other reasons for this shift in North Sámi, including a potentially detrimental influence of the North Sámi orthography that does not distinguish between the two geminate types. An additional source of variation and instability might be the effects of majority languages, in this case Norwegian and Finnish (cf. Hiovain and Šimko, 2019). However, the influence of majority languages is somewhat difficult to disentangle from the dialectal features, as - in our data as well as in the entire Finnmark North Sámi population-Western dialect speakers live predominantly in Norway and the most North Sámi speakers living in Finland use Eastern dialect. In fact, it is quite possible that the dialectal differences themselves, e.g., in terms of phonetic features, are consequences of the majority language influences.

Also, given typological differences between these two majority languages, the phonetic realization of the contrast might be shifting toward other means. For example, the Q2-Q3 contrast might be co-signalled by other than durational means such as fundamental frequency or intensity (cf. Lippus et al., 2011; Vainio et al., 2010), and the degree to which these alternative means are used in the two dialects might reflect the characteristics of the majority language. Adding these characteristics to future analysis could bring new answers to the question of stability and variation of the ternary length contrasts in North Sámi. A hypothesis can be raised from the answers of the speakers analyzed here: after recording, when asked how do they perceive the difference between Q2 and Q3 geminates, they mentioned differences in both duration and intensity.
The fundamental frequency contours and intensity values in relationship with quantity have been studied in Lule (Fangel-Gustavson et al., 2014), Inari (Türk et al., 2019), and Skolt Sámi (McRobbie-Utasi et al., 2007). It has been found that in all these languages, duration is the main component of the quantity realization, and it seems to influence the intensity of the vowels surrounding the intervocalic consonant. In the case of fundamental frequency, some distinct patterns for different quantity degrees were suggested in Skolt and Inari Sámi.

Our results document an ongoing shift in realization of a very rare typological feature in an endangered minority language, and can contribute to the understanding the possible ways of implementing phonological quantity contrast in different languages as well as, more generally, the mechanisms and processes of language change. The results thus provide a clear argument for the need of reliable phonetic research and a thorough documentation of every hitherto under-researched and under-documented language before this priceless source of linguistic material gets irreversibly lost.

\section{ACKNOWLEDGMENTS}

This research was partly supported by a Finno-Ugrian Society grant to the first author. We are very thankful for all the North Sámi speakers who participated in the research. We are also grateful to Tuomas Magga, Jussi Ylikoski, and Pärtel Lippus for their help and inspiration.

Aikio, A., Arola, L., and Kunnas, N. (2015). "Variation in North Saami," in Globalising Sociolinguistics: Challenging and Expanding Theory, edited by D. Smakman and P. Heinrich (Routledge, London), pp. 243-255.

Aikio, A., and Länsman, H. (2005). Pohjoissaamen Alkeiskurssi (A North Sámi Textbook for Beginners) (University of Oulu).

Baal, B. A. B., Odden, D., and Rice, C. (2012). "An analysis of North Saami gradation," Phonology 29(2), 165-212.

Bates, D., Mächler, M., Bolker, B., and Walker, S. (2015). "Fitting linear mixed-effects models using lme4," J. Stat. Softw. 67(1), 1-48.

Boersma, P. (2002). "Praat, a system for doing phonetics by computer," Glot Int. 5, 341-345.

Bye, P., Sagulin, E., and Toivonen, I. (2009). "Phonetic duration, phonological quantity and prosodic structure in Inari Saami," Phonetica 66(4), 199-221.

Collinder, B. (1929). Über den Finnisch-Lappischen Quantitätswechsel (The Finnic-Saamic Quantity Alternation) (Lundequist, Uppsala).

Eek, A., and Meister, E. (1997). "Simple perception experiments on Estonian word prosody: Foot structure vs. segmental quantity," in Estonian Prosody: Papers from a Symposium, edited by I. Lehiste and J. Ross (Institute of Estonian Language), pp. 71-99.

Engstrand, O. (1987). "Durational patterns of Lule Sámi phonology," Phonetica 44(2), 117-128.

Fangel-Gustavson, N., Ridouane, R., and Morén-Duolljá, B. (2014). "Quantity contrast in Lule Saami: A threeway system," in Proceedings of 10th ISSP, May 5-8, Cologne, Germany, pp. 106-109.

Hasselbrink, G. (1981). "Südlappisches Wörterbuch I-III” (“A dictionary of South Sámi”), Skr Dialekt-och folkminnesarkivet i Uppsala, Ser. C 1985(4), 1-1488.

Hiovain, K., and Šimko, J. (2019). "Duration patterns in finnmark north sámi quantity," in Proceedings of the International Congress of Phonetic Sciences, August 5-9, Melbourne, Australia, pp. 1560-1564.

Hothorn, T., Bretz, F., and Westfall, P. (2008). "Simultaneous inference in general parametric models," Biometr. J. 50(3), 346-363.

Itkonen, T. (1916). "Venäjänlapin konsonanttien astevaihtelu: Koltan, kildinin ja turjan murteiden mukaan" ("Grade alternation of consonants in 
Russian Sámi according to the dialects of Skolt, Kildin and Ter Sámi”), Mémoires de la Société Finno-Ougrienne 39, 1-120.

Kahn, L., and Valijärvi, R.-L. (2017). North Sámi: An Essential Grammar (Routledge, London).

Karlsson, F., Sullivan, K. P., Svonni, M., Van Doorn, J., and Wennstedt, O. (2008). "The acoustic manifestation of consonant gradation in Northern Sami," J. Acoust. Soc. Am. 123(5), 3885.

Kisler, T., Reichel, U., and Schiel, F. (2017). "Multilingual processing of speech via web services," Comput. Speech Lang. 45, 326-347.

Korhonen, M. (1981). Johdatus Lapin Kielen Historiaan (An Introduction to the History of the Sámi Languages) (Suomalaisen Kirjallisuuden Seura, Helsinki), Vol. 370.

Krull, D. (1999). "Foot isochrony in Estonian conversational speech," Gothenburg Papers Theor. Ling. 81, 97-100.

Kulonen, U.-M., Seurujärvi-Kari, I., and Pulkkinen, R. (2005). The Saami: A Cultural Encyclopaedia (Suomalaisen Kirjallisuuden Seura, Helsinki).

Ladefoged, P. (2003). Phonetic Data Analysis: An Introduction to Fieldwork and Instrumental Techniques (Wiley-Blackwell, New York).

Ladefoged, P., and Maddieson, I. (1996). The Sounds of the World's Languages (Blackwell, Oxford, UK), Vol. 1012.

Lagercrantz, E. (1927). Strukturtypen und Gestaltwechsel im Lappischen (The Structural Types and Root Alternation in Sámi) (SuomalaisUgrilainen Seura, Helsinki, Finland).

Lehiste, I. (1960). "Segmental and syllabic quantity in Estonian," Am. Stud. Uralic Ling. 1, 21-82.

Lehiste, I. (1965). "The function of quantity in Finnish and Estonian," Language 41(3), 447-456.

Lehiste, I. (1970). Suprasegmentals (Massachusetts Institute of Technology, Cambridge, MA).

Lehiste, I. (2008). Livonian Prosody (Suomalais-Ugrilainen Seura, Helsinki), Vol. 255.

Lippus, P., Pajusalu, K., and Allik, J. (2011). "The role of pitch cue in the perception of the Estonian long quantity," in Prosodic Categories: Production, Perception and Comprehension (Springer, New York), pp. 231-242.

Magga, T. (1984). Duration in the Quantity of Bisyllabics in the Guovdageaidnu Dialect of North Lappish (University of Oulu, Oulu, Finland), Vol. 11.

Markus, E., Lippus, P., Pajusalu, K., and Teras, P. (2012). "Three-way opposition of consonant quantity in Finnic and Saamic languages," in Nordic Prosody: Proceedings of the 11th Conference, April 18-20, Tartu, Estonia, pp. 225-234.
McRobbie-Utasi, Z., Toivonen, I., and Nelson, D. (2007). "The instability of systems with ternary length distinctions: The Skolt Saami evidence," Amsterdam Stud. Theory Hist. Ling. Sci. Ser. 4 288, 167.

Moseley, C. (2010). Atlas of the World's Languages in Danger (UNESCO, Paris).

Nickel, K. P., and Sammallahti, P. (2011). Nordsamisk Grammatikk (A Grammar of North Sámi) (Davvi Girji, Kárášjohka, Norway).

Nielsen, K. (1926). Larebok i Lappisk (AW Broggers Boktrykkeri, Oslo).

$\mathrm{R}$ Core Team (2019). "R: A language and environment for statistical computing," https://www.R-project.org/ (Last viewed April 28, 2019).

Remijsen, B., Ayoker, O. G., and Jørgensen, S. (2019). "Ternary vowel length in Shilluk," Phonology 36(1), 91-125.

Remijsen, B., and Gilley, L. (2008). "Why are three-level vowel length systems rare? Insights from Dinka (Luanyjang dialect)," J. Phon. 36(2), 318-344.

Remijsen, B., and Manyang, C. A. (2009). "Luanyjang Dinka,” J. Int. Phon. Assoc. 39(1), 113-124.

Sammallahti, P. (1977). "Norjansaamen Itä-Enontekion murteen äänneoppi" ("The phonology of the Eastern Eanodat dialect of North Sámi”), Memoires de la Societe Finno-Ougrienne 160, 110-113.

Sammallahti, P. (1994). Sámi-Suoma-Sámi Sátnegirji, SaamelaisSuomalais-Saamelainen Sanakirja. (2. Painos) (A Finnish-Sámi-Finnish Dictionary) (Girjegiisá Oy Ohcejohka Finland).

Sammallahti, P. (1998). The Saami Languages: An Introduction (Davvi Girji, Karasjok, Norway).

Scheller, E. (2011). "The Saami language situation in Russia," Uralica Helsingiensia 5, 79-96.

Schiel, F. (1999). "Automatic phonetic transcription of non-prompted speech," in Proceedings of the XIVth International Congress of Phonetic Sciences, August 1-7, San Francisco, CA, pp. 607-610.

Türk, H., Lippus, P., Pajusalu, K., and Teras, P. (2019). "The acoustic correlates of quantity in Inari Saami," J. Phon. 72, 35-51.

Vainio, M., Järvikivi, J., Aalto, D., and Suni, A. (2010). "Phonetic tone signals phonological quantity and word structure," J. Acoust. Soc. Am. 128(3), 1313-1321.

von Gertten, D. Z. (2015). "Huvuddrag i umesamisk grammatik" ("The main characteristics of Ume Sámi grammar”), Master's thesis, University of Oslo, Oslo, Norway.

Wilbur, J. K. (2007). "Syllable structures and stress patterns in Kildin Saami," Master's thesis, Institut für Linguistik der Universität Leipzig, Leipzig, Germany.

Wilbur, J. (2014). A Grammar of Pite Saami (Language Science Press, Berlin). 